\title{
Traumatic Optic Neuropathy: Our Experience with Combined Therapy
}

\author{
Sudesh Kumar ${ }^{1}$ Amit Joshi ${ }^{2}$ Rajeev Tuli ${ }^{3}$ Narvir Chauhan ${ }^{4}$ \\ ${ }^{1}$ Department of Otolaryngology and Head Neck Surgery, Dr Rajendra \\ Prasad Government Medical College, Kangra, Himachal Pradesh, \\ India \\ 2 Department of Neurosurgery, Dr Rajendra Prasad Government \\ Medical College, Kangra, Himachal Pradesh, India \\ ${ }^{3}$ Department of Ophthalmology, Dr Rajendra Prasad Government \\ Medical College, Kangra, Himachal Pradesh, India \\ ${ }^{4}$ Department of Radiodiagnosis, Dr Rajendra Prasad Government \\ Medical College, Kangra, Himachal Pradesh, India \\ Indian J Neurotrauma 2022;19:84-88.
}

\begin{abstract}
Address for correspondence Sudesh Kumar, MBBS, MS, DNB, Department of Otolaryngology \& Head Neck Surgery, Dr Rajendra Prasad Government Medical College, Kangra 176001, Himachal Pradesh, India (e-mail: sudeshkumar74@gmail.com).
\end{abstract}

\section{Abstract}

Keywords

- combined therapy

- endoscopic decompression

- steroid

- traumatic optic neuropathy

- visual outcome

Objective Traumatic optic neuropathy (TON) is an important cause of severe vision impairment after sustaining a closed head injury. This study describes the safety and efficacy of combined therapy in the management of TON.

Methods A retrospective analysis of 23 consecutive cases of unilateral TON managed with combined therapy (steroid and surgery) were performed. Statistical analysis of patient characteristic, timing of vision loss, radiological and intraoperative findings, and pre- and post-treatment vision were compared to assess the prognostic factors. Results Seventeen patients (85\%) had vision improvement with combined therapy. Three patients $(15 \%)$, who recorded no improvement, initially presented with no perception of light, and loss was sudden and immediate. With steroids, 9 patients improved, all of them presented with perception of light (PL) or better and vision improved to (6/6 in five, 6/9 in one, 6/18 in 3). Eleven patients (6 PL-ve and $5 \mathrm{PL}+$ ve after failed steroid therapy) underwent endoscopic optic nerve decompression and eight had improvement in vision. The status of vision at presentation was only statically significant prognostic factor $(p<0.02)$. Others prognostic factors, for example, time of starting treatment, surgery, and presence of fracture in optic canal, were not found statistically significant $(p>0.05)$. There were no significant intra- and postoperative complications.

Conclusion Combined therapy is safe and effective in management of TON. Mild form injury with some preserved vision at presentation respond well to steroids, while endoscopic nerve decompression should be reserved in cases with failed steroid therapy.
\end{abstract}

published online

December 7, 2021
DOI https://doi.org/ $10.1055 / \mathrm{s}-0041-1739479$ ISSN $0973-0508$.

\footnotetext{
(c) 2021. Neurotrauma Society of India. All rights reserved.

This is an open access article published by Thieme under the terms of the Creative Commons Attribution-NonDerivative-NonCommercial-License, permitting copying and reproduction so long as the original work is given appropriate credit. Contents may not be used for commercial purposes, or adapted, remixed, transformed or built upon. (https://creativecommons.org/ licenses/by-nc-nd/4.0/)

Thieme Medical and Scientific Publishers Pvt. Ltd., A-12, 2nd Floor, Sector 2, Noida-201301 UP, India
} 


\section{Introduction}

The reported incidence of traumatic optic neuropathy (TON), following a closed head injury, is around $5 \%{ }^{1}$ TON is characterized by vision loss or deterioration following a closed head injury along with the presence of relative afferent pupillary defect (RAPD). ${ }^{2}$ The extent of vision loss after TON is variable and approximately $50 \%$ of cases are left with permanent nonserviceable vision. ${ }^{3}$ It is further classified into direct and indirect. Direct TON is rare and results from penetrating globe injury or fracture impinging on the nerve. The indirect type commonly occurs at the optic canal level, where blunt frontal force is maximally concentrated. These shearing forces cause compression of the nerve by inducing intraneural edema, resulting in vision deterioration. ${ }^{4}$

The treatment of TON is still a matter of debate, and it includes observation alone, steroid therapy, surgical decompression alone, or combination with steroids. ${ }^{5}$ Description of these different modalities and the variable outcomes can be due to the absence of standardized treatment protocol in managing such cases. Also, low incidence of TON, different treatment protocols, and absence of randomized control trial add more to its uncertainty.

Decompression of the optic nerve can be performed through various approaches, including transcranial, transconjunctival, external ethmoidectomy, and endoscopic approaches. ${ }^{6}$ In endoscopic optic nerve decompression (EOND), the bony medial wall of the optic canal is removed $180^{\circ}$, allowing the edematous nerve to decompress, and is the most sought approach these days. It was popularized around 1990, but its indications, efficacy, and timing are still a matter of debate. ${ }^{7}$

We are presenting the data of case series of 20 consecutive patients of TON managed in our department with combined therapy and assessing its safety and efficacy in terms of visual improvement.

\section{Materials and Methods}

In this retrospective study, medical records of 23 consecutive patients of traumatic optic nerve managed by combined therapy in the department of otolaryngology and head and neck surgery from June 2017 till May 2020 were analyzed. All patients presented with a decrease or loss of vision following sustaining head trauma, RAPD on eye examination, evidence of edema, or fracture optic canal on radiology. All patients received steroid therapy and underwent EOND if failure of vision improvement and were in follow-up for a minimum of 3 months. All patients were enrolled after being explained about the diagnosis, treatment options, and risks and benefits of treatment; informed consent was obtained. Three patients did not complete the therapy, so were excluded from the study.

A neurosurgeon and ophthalmologist evaluated all cases at presentation and documented their initial vision, neurological status, and Glasgow coma scale (GCS) score.
Subsequently, the vision was checked periodically to assess the response from treatment. Although it is difficult to evaluate vision in unconscious patients, the presence of RAPD and evidence of fracture of the optic canal on radiology can suggest TON. The flash visual evoked potentials (VEP) test has recently been found to be useful for assessing visual functioning in patients with severe head injuries and unconscious patients.

High-resolution computed tomography (HRCT) of orbit, nose, and paranasal sinus was done in all cases to assess any fracture of the optic canal, edema of the nerve, and pneumatization of the sphenoid sinus. When the axial and coronal diameters of the optic nerve were greater than $4.5 \mathrm{~mm}$ on a CT scan, they were considered edematous.

All patients initially were treated with injection of methyl-prednisolone $30 \mathrm{mg} / \mathrm{kg}$ loading dose followed by $5.4 \mathrm{mg} / \mathrm{kg} / \mathrm{hr}$ for 6 hours for 2 days, if they presented within 7 days of trauma, but in cases presenting later than 7 days, tapering oral steroids ( $1 \mathrm{mg} / \mathrm{kg} /$ day) was given. Those improved were discharged on tapering oral steroid for 2 weeks and kept on follow-up.

Failure in the improvement of vision or deterioration despite steroid therapy, persistent perception of light (PL)ve vision, or evidence of fracture in the optic canal on CT scan were the indications for EOND, which were performed under general anesthesia by the author (S.K.) using Messerklinger's technique. Ipsilateral uncinectomy was done after local infiltration and maxillary sinus ostium was identified and widened. The bulla ethmoidalis representing anterior ethmoids air cells were uncapped, and ground lamella was opened up to access the posterior ethmoid. The sphenoid sinus ostium was identified and widened. The landmarks on the lateral wall, for example, carotid bulge, optic canal, and opticocavernous recess were identified. The lamina papyracea was delineated and the orbital apex was drilled. Fractures on the sphenoid lateral wall and optic canal were noted and any fracture fragments impinging on the nerve were removed. In case the optic canal was found normal, it was thinned out with a drill. A sickle knife was used to incise the sheath horizontally, and the fibers of the annulus of Zinn were cut to allow for better decompression of nerve fibers. The medicated pack was kept and then removed after 48 hours. The vision was checked regularly and documented, and vision at 3 months or final follow-up, if follow-up was less than 3 months, was considered final.

The vision was considered improved after treatment (a) if vision increased to 3 lines or more on the Snellen test, (b) it changed from PL-ve to PL + ve, (c) recorded changes from $\mathrm{PL}+$ ve to hand movement or better. For quantitative assessment of the degree of visual improvement, visual acuity was converted to the logarithm of minimum angle of resolution (log MAR) scale, as shown in - Table $\mathbf{1}$. Statistical analysis was performed using Fisher's exact test with preoperative vision status, the onset of loss of vision, combined and steroid therapy, fracture of the optic canal, and loss of consciousness and GCS score as prognostic factors. The odds ratio was calculated and $p$-value of $<0.05$ was considered significant. 
Table 1 Conversion scale of visual acuity

\begin{tabular}{|l|l|}
\hline Visual acuity & Log MAR \\
\hline PL-ve (no perception of light) & -4.70 \\
\hline $\mathrm{PL}+$ ve (perception of light) & -3.70 \\
\hline Hand movements & -2.70 \\
\hline $1 / 60$ & -1.70 \\
\hline $2 / 60$ & -1.40 \\
\hline $3 / 60$ & -1.30 \\
\hline $6 / 60$ & -1.00 \\
\hline $6 / 30$ & -0.70 \\
\hline $6 / 24$ & -0.60 \\
\hline $6 / 18$ & -0.48 \\
\hline $6 / 12$ & -0.30 \\
\hline $6 / 9$ & -0.18 \\
\hline $6 / 6$ & 0.00 \\
\hline $6 / 5$ & 0.12 \\
\hline $6 / 4$ & 0.18 \\
\hline
\end{tabular}

\section{Results}

Fourteen patients were male and six female with a male to female ratio of 2.3 to 1 and age range of 11 to 52 years (mean $=31.15)$. All patients presented with unilateral TON (-Table 2). Thirteen patients had right and seven had left side eye involvement. The majority of patients were younger than 30 years (40\%). The mode of sustaining trauma was a motor vehicle accident (65\%) while $35 \%$ had a history of fall from height. Thirteen patients had a brief loss of consciousness (65\%), and GCS scores at presentation showed that 12 had mild and 8 had moderate head injuries.

Nine of the 14 patients with PL + ve or better vision had improved vision with steroid therapy, while none of the PLve patients $(n=6)$ improved with steroid therapy; all PL-ve were subjected to surgery in addition to steroids. Therefore, 11 patients ( 6 PL-ve and $5 \mathrm{PL}+\mathrm{ve}$ ) underwent surgery. Eight patients (5 PL+ve and three PL-ve) experienced an improvement in their vision after surgery, while three patients did not. All cases were operated in a range of 2 to 12 days (average $=5.75$ ) after sustaining trauma. Due to the fact that all patients came from different parts of our state and because our state is hilly, there were challenges in transportation, and some of the patients were not physically fit for general anesthesia.

On CT scan, 14 (73.68\%) had evidence of an optic canal or orbital wall fracture. The remaining six $(P L+v e)$ patients without evidence of fracture improved with steroid treatment, suggesting a lesser degree of optic nerve injury. In 10 patients, intraoperatively, an orbital apex or optic canal fracture was seen, and among these, five patients had an additional fracture of the skull, maxilla, or other facial bones.

One statistically significant prognostic factor in this study was preoperative visual status; if it was PL+ or better, all had improved, but in PL-, only 50\% cases had improved
( $p=0.017$ ). Other prognostic factors including the onset of loss of vision versus delayed ( $p=0.21$ ), the timing of surgery $(p=0.23)$, treatment starting before or after 48 hours $(p=0.05)$, and optic canal fracture $(p=0.53)$ were not significant. By using log MAR for quantitative vision, the mean pretreatment value was -2.721 , while posttreatment, it was -1.33 with a standard deviation of 1.6077 and 1.726 , respectively. The value $\mathrm{t}=-5.572$ and was statistically significant $(p<0.05)$.

There were no intra and postoperative complications. After discharge, all were kept on follow-up. The final vision was recorded at 1 and 3 months or the last follow-up of the patient. The follow-up range was 3 to 24 months (mean 7.75).

\section{Discussion}

In this study, $70 \%$ of cases were males, and the majority of them were in their early third decade of life $(n=7)$, which is consistent with the description in a recent study by Yu et al. ${ }^{8}$ The majority of patients $(65 \% ; n=13)$ sustained trauma in motor vehicle accidents, similar to the study by Ropposch et al $(58 \% ; n=24){ }^{9}$

The exact mechanism and pathophysiological events of TON are still not clearly understood but studies have documented that when sudden blunt force is applied to the frontal area, it is transmitted backward and is maximally concentrated around the optic canal area. ${ }^{10}$ So, there is increased intracanalicular pressure, leading to intraneural edema. This results in alteration or interruption of axoplasmic transportation or microvascular circulation, resulting in deterioration of vision. These events may be initially reversible, but progressive compression may lead to irreversible neural damage. ${ }^{11}$ So, treatment goal is to relieve edema either medically or by surgical decompression at the earliest.

Till now there is no clear consensus on the optimum treatment of TON, and it is still a controversial topic. In 1951, Hoper first described the intracranial approach for OND, ${ }^{12}$ but its outcome was poor. Later in 1980, Spoor et al described steroid therapy, which becomes very popular. ${ }^{13}$ The endoscopic approach was described in 1990 by Fujitani et al. ${ }^{6}$ Observation alone may result in improvement in around $20 \%,{ }^{14}$ but it may not be considered as best option, especially when vision is PL-ve. High-dose steroid therapy has been described as the primary treatment for TON, and EOND is reserved in cases of failed vision improvement with steroid therapy. ${ }^{15}$

In optic canal decompression (OCD), a part of the bony canal is removed, creating a space around the nerve and allowing it to decompress which relieves the edema. ${ }^{16}$ Transnasal approaches for OCD, for example, external and endoscopic have been described in the literature, although endoscopic is most favored these days. ${ }^{6}$ It has advantages of excellent visualization of the optic canal, less morbidity, preservation of olfaction, and shorter recovery time as compared with an external one. ${ }^{17}$

In this study overall, 85\% of patients had improvement in vision with combined therapy, which is comparable or even 
Traumatic Optic Neuropathy: Steroids and Endoscopic Nerve Decompression Kumar et al. 87

\begin{tabular}{|c|c|c|c|c|c|c|c|c|c|c|c|c|c|c|c|c|c|c|c|c|}
\hline 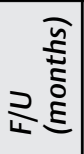 & $\stackrel{\infty}{\sim}$ & 0 & 0 & $\stackrel{\searrow}{\sim}$ & $\because$ & 6 & a & $\nabla$ & 6 & $\infty$ & 6 & $n$ & $a$ & $m$ & 0 & $\nabla$ & $\nabla$ & 6 & $\nabla$ & $m$ \\
\hline 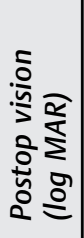 & $\begin{array}{l}\widehat{O} \\
\stackrel{8}{-} \\
1 \\
\\
\frac{0}{0} \\
\frac{0}{0}\end{array}$ & 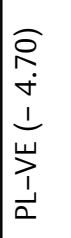 & 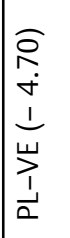 & 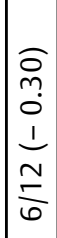 & 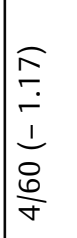 & 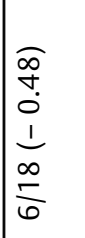 & $\frac{a}{\frac{0}{0}}$ & 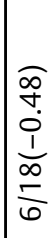 & $\frac{\widehat{c}}{\frac{0}{0}}$ & $\begin{array}{l}\widehat{a} \\
\frac{0}{6}\end{array}$ & 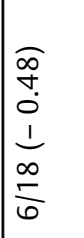 & $\begin{array}{l}0 \\
\frac{\infty}{0} \\
\frac{1}{1} \\
\frac{1}{0} \\
\frac{0}{b}\end{array}$ & $\frac{a}{\frac{0}{b}}$ & 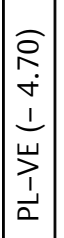 & 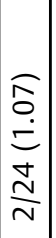 & 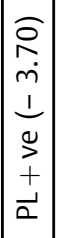 & $\begin{array}{l}\frac{\widehat{\sigma}}{\sigma} \\
0 \\
1 \\
\frac{1}{\infty} \\
\frac{0}{6}\end{array}$ & 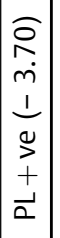 & $\begin{array}{l}\frac{0}{0} \\
\stackrel{0}{0} \\
1 \\
\frac{\infty}{\infty} \\
\frac{0}{6}\end{array}$ & $\frac{\widehat{a}}{\frac{0}{b}}$ \\
\hline 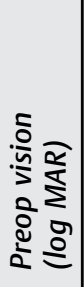 & 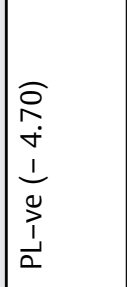 & 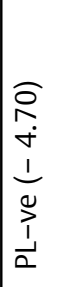 & 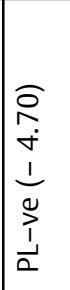 & 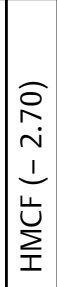 & 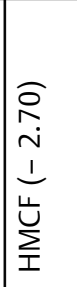 & 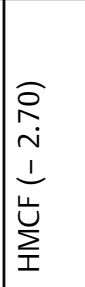 & 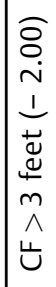 & 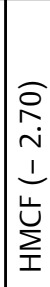 & 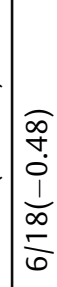 & $\begin{array}{l}\widehat{\infty} \\
\stackrel{\infty}{+} \\
0 \\
\frac{1}{\infty} \\
\frac{0}{6} \\
\frac{0}{6}\end{array}$ & 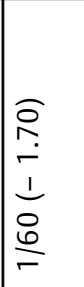 & 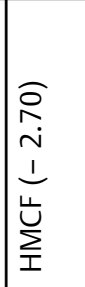 & 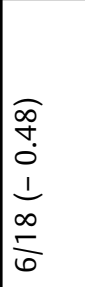 & 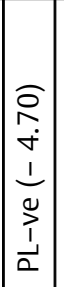 & 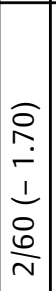 & 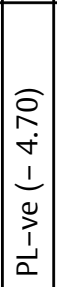 & 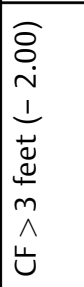 & 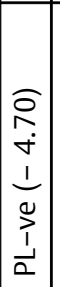 & $\begin{array}{l}a \\
i \\
m \\
m \\
i \\
\stackrel{a}{2} \\
+ \\
\vec{a}\end{array}$ & $\mid \begin{array}{c}\frac{0}{0} \\
\frac{0}{0} \\
1 \\
\frac{0}{b} \\
\end{array}$ \\
\hline 气ิ 气ิ & $\simeq$ & $\nabla$ & $\nabla$ & $\sim$ & $\infty$ & $\nabla$ & $\overline{\bar{z}}$ & $\nabla$ & $\overline{\bar{z}}$ & $\overline{\bar{z}}$ & $\overline{\bar{z}}$ & $\overline{\bar{z}}$ & $\overline{\bar{z}}$ & $\nabla$ & $m$ & $\sim$ & $\overline{\bar{z}}$ & $\because$ & $\overline{\bar{z}}$ & $\overline{\bar{z}}$ \\
\hline 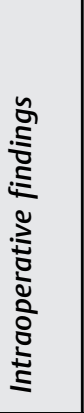 & 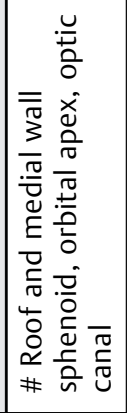 & 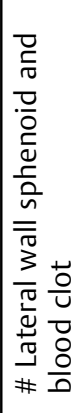 & 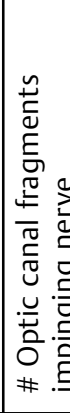 & 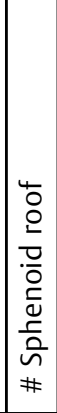 & 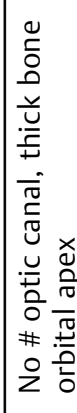 & 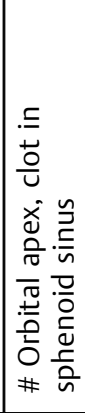 & $\frac{\bar{z}}{\bar{z}}$ & 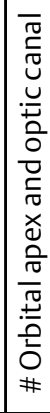 & $\bar{z}$ & $\overline{\bar{z}}$ & $\overline{\bar{z}}$ & $\overline{\bar{z}}$ & $\overline{\bar{z}}$ & 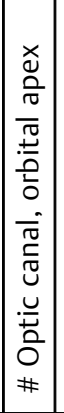 & 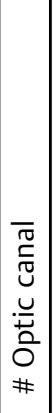 & 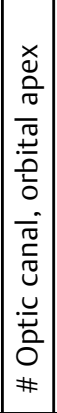 & $\overline{\bar{z}}$ & 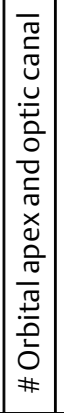 & $\overline{\bar{z}}$ & $\overline{\bar{z}}$ \\
\hline 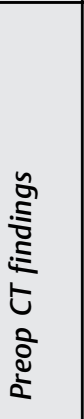 & 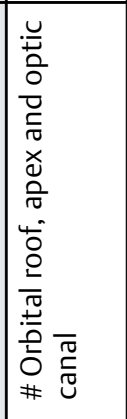 & 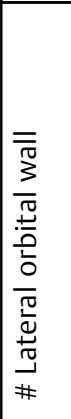 & 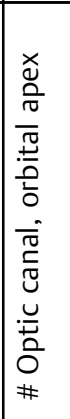 & 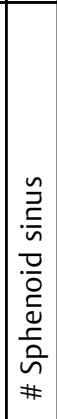 & 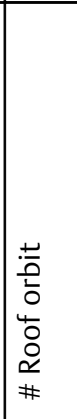 & 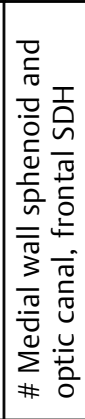 & 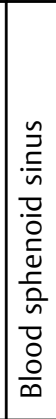 & 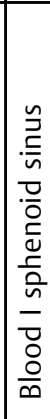 & 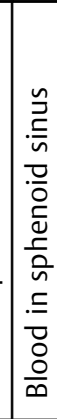 & 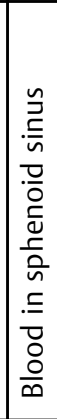 & 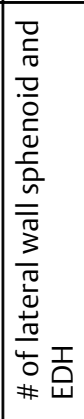 & 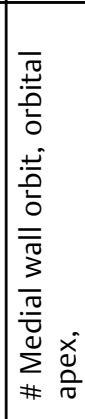 & 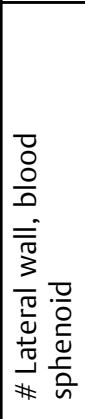 & 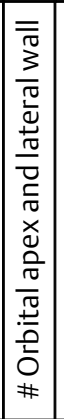 & 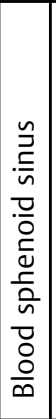 & 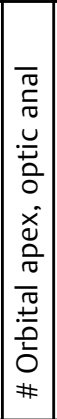 & 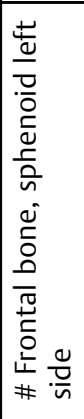 & 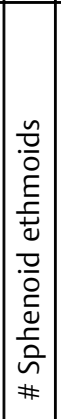 & 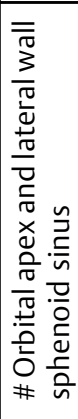 & 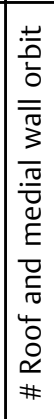 \\
\hline 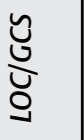 & $\frac{\stackrel{v}{y}}{\stackrel{y}{x}}$ & $\frac{m}{\frac{m}{y}}$ & $\frac{\stackrel{n}{y}}{\stackrel{y}{y}}$ & $\frac{0}{\frac{\sigma}{0}}$ & $\frac{m}{\frac{m}{y}}$ & $\frac{\sim}{\frac{N}{y}}$ & $\frac{m}{\frac{m}{\alpha}}$ & $\frac{\frac{1}{z}}{\frac{z}{z}}$ & $\frac{m}{\frac{m}{y}}$ & $\frac{\frac{1}{0}}{\frac{0}{z}}$ & $\frac{\bar{z}}{\bar{y}}$ & $\frac{m}{\frac{m}{0}}$ & $\frac{m}{\frac{m}{y}}$ & \begin{tabular}{|l|}
$\frac{\partial}{y}$ \\
$\stackrel{y}{\nu}$
\end{tabular} & $\frac{\stackrel{v}{\bar{y}}}{\stackrel{y}{\check{y}}}$ & $\frac{\Xi}{\bar{y}}$ & $\frac{m}{\frac{m}{o}}$ & $\frac{\stackrel{v}{\bar{y}}}{\stackrel{\frac{y}{y}}{\supset}}$ & $\frac{\mathfrak{y}}{\stackrel{y}{y}}$ & $\frac{\frac{\pi}{0}}{\frac{1}{2}}$ \\
\hline 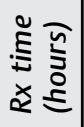 & $\underset{\wedge}{\stackrel{\infty}{+}}$ & $\begin{array}{l}\stackrel{\infty}{+} \\
\wedge\end{array}$ & $\begin{array}{l}\stackrel{\infty}{+} \\
\wedge\end{array}$ & $\stackrel{\infty}{\stackrel{\infty}{\vee}}$ & $\begin{array}{l}\stackrel{\infty}{+} \\
\wedge\end{array}$ & 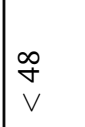 & $\begin{array}{l}\stackrel{\infty}{+} \\
\wedge\end{array}$ & $\underset{\vee}{\stackrel{\infty}{\vee}}$ & $\underset{\vee}{\stackrel{\infty}{+}}$ & $\begin{array}{l}\stackrel{\infty}{+} \\
\vee\end{array}$ & \begin{tabular}{|l}
$\stackrel{\infty}{+}$ \\
$\wedge$
\end{tabular} & 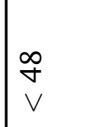 & $\begin{array}{l}\stackrel{\infty}{+} \\
\vee\end{array}$ & \begin{tabular}{|l|} 
\\
$\stackrel{\infty}{+}$ \\
$\wedge$
\end{tabular} & $\begin{array}{l}\infty \\
\stackrel{\infty}{+} \\
\vee\end{array}$ & $\begin{array}{c}\infty \\
\stackrel{\infty}{+} \\
\vee\end{array}$ & 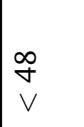 & 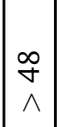 & $\begin{array}{l}\stackrel{\infty}{+} \\
\vee\end{array}$ & 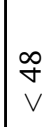 \\
\hline$\frac{8}{5}$ & $\vec{\alpha}$ & $\vec{\alpha}$ & \pm & $\vec{\alpha}$ & $\vec{\alpha}$ & \pm & $\vec{\alpha}$ & \pm & $\vec{\alpha}$ & \pm & \pm & $\varpi$ & $\ddot{\alpha}$ & $\vec{a}$ & $\ddot{\alpha}$ & $\ddot{\sim}$ & \pm & $\vec{\alpha}$ & $\ddot{a}$ & $\vec{\alpha}$ \\
\hline $\begin{array}{rl} & \overline{\hat{n}} \\
0 & 0 \\
0 & 0 \\
0\end{array}$ & 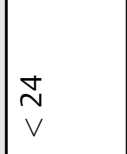 & $\stackrel{\nabla}{\underset{V}{V}}$ & $\stackrel{\nabla}{\underset{V}{V}}$ & $\stackrel{\stackrel{\nabla}{\sim}}{\wedge}$ & $\stackrel{\searrow}{\stackrel{\Xi}{\sim}}$ & 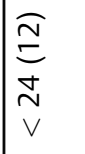 & $\stackrel{\stackrel{\searrow}{\sim}}{\wedge}$ & $\stackrel{\stackrel{\sim}{\sim}}{\wedge}$ & $\stackrel{\stackrel{D}{N}}{\wedge}$ & $\stackrel{\stackrel{\sim}{\sim}}{\wedge}$ & $\stackrel{\stackrel{J}{\sim}}{\wedge}$ & $\stackrel{\sim}{\underset{V}{v}}$ & $\underset{\wedge}{\stackrel{\Xi}{\sim}}$ & \begin{tabular}{|l}
$\stackrel{\sim}{N}$ \\
$\vee$
\end{tabular} & 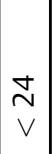 & $\stackrel{\searrow}{\underset{\vee}{\vee}}$ & $\stackrel{\searrow}{\sim}$ & $\stackrel{\sim}{\underset{\sim}{\vee}}$ & $\stackrel{\sim}{\underset{V}{\vee}}$ & 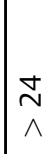 \\
\hline 哀 & $\frac{\mathrm{L}}{\mathrm{O}}$ & $\sum_{\infty}^{\infty}$ & $\underset{\Sigma}{\Sigma}$ & $\frac{\sum}{\sigma}$ & $\sum_{\text {ก }}$ & $\frac{u}{9}$ & $\frac{\sum}{\dot{a}}$ & 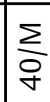 & $\underset{I}{\Sigma}$ & $\underset{\substack{m \\
m}}{\sum}$ & $\sum_{\infty}^{\infty}$ & $\frac{u}{\mathcal{Y}}$ & 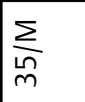 & 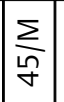 & 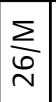 & $\frac{\stackrel{u}{\infty}}{\stackrel{\infty}{+}}$ & $\frac{\omega}{\stackrel{n}{N}}$ & 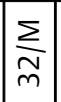 & $\sum_{\substack{n \\
m}}$ & $\stackrel{\text { 늗 }}{=}$ \\
\hline $\begin{array}{l}\stackrel{8}{1} \\
\dot{n}\end{array}$ & - & $\sim$ & $m$ & $\nabla$ & เn & 0 & $r$ & $\infty$ & $a$ & $\stackrel{\circ}{\circ}$ & $\mp$ & $\simeq$ & $\underline{m}$ & $\nabla$ & $\stackrel{\llcorner}{\llcorner}$ & $\stackrel{\bullet}{\bullet}$ & $\Sigma$ & $\stackrel{\infty}{\stackrel{0}{2}}$ & $\stackrel{9}{-}$ & $\stackrel{N}{ }$ \\
\hline
\end{tabular}


better to that described in the literature (60.9-71.1\%). ${ }^{18}$ Similarly, Li et al described 237 patients of TON treated with combined therapy who recorded better vision improvement compared with steroid only (55\% vs. $51 \%)^{19}$. They also found that cases with gradual onset of loss of vision have a better prognosis than sudden onset ( $68 \%$ vs. $42 \%$ ). Similarly, we found that vision improvement was $100 \%$ if the onset of loss of vision was more than 24 hours; probably such cases sustained a milder form of injury to the nerve.

Yang et al described that TON with PL-ve has a poorer prognosis than $\mathrm{PL}+$ ve or better vision (efficacy rate $26.45 \mathrm{vs.}$ 83.3\%). ${ }^{19}$ Similarly, in our study, vision improvement was $50 \%$ (PL -ve) versus $100 \%$ ( $P L+$ ve), and it was statistically significant $(p<0.05)$. Immediate loss of vision was seen in all 6 PL-ve cases (2 to 4 hours after trauma); also, they all had a loss of consciousness for few hours. However, their GCS score suggested mild head injuries in two patients and moderate injuries in four patients. After combined therapy, $50 \%$ of cases $(n=3)$ had vision improvement, and it improved to PL + ve $(n=2)$ and $6 / 60(n=1)$. This was comparable to the results reported in the literature (44.7-48.78\%). ${ }^{8}$

To date, no study had been performed showing a correlation of the severity of head injury with outcome in TON patients. However, in this study, we found that patients with mild head injury $(n=12)$, all PL + ve of better $(n=10)$ and none of PL-ve $(N=2)$ had vision improvement, while for moderate injury $(n=8)$, all PL + ve $(n=4)$ and 3 PL-ve had vision improvement. However, Fisher exact test failed to show a statistically significant $(p<1)$ rate of vision improvement among the two groups.

The timing of EOND is also debatable. Song ${ }^{16}$ et al described that in PL-ve vision cases, if surgery is performed after 3 days of trauma, they had poorer outcomes ( $p=0.047)$. Contrary to our 3 PL-ve cases, vision improved after surgery, and EOND was performed on an average 10.66 days after trauma. The delay was due to patients suffering from other life-threatening injuries, a referral from other hospitals, time is taken for consent, and fitness for general anesthesia. Improvement in vision despite a delay in surgery might be due to the fact that the exact mechanism and pathophysiology of TON is still not fully understood. ${ }^{19}$

\section{Conclusion}

InTON, combined therapy has shown to be highly successful in improving vision. Once neurosurgery clearance has been obtained, high-dose steroid therapy should be started as soon as possible. When steroid therapy fails, nerve decompression should be attempted endoscopically. In our study, no major complications were observed, which suggests that combined therapy is safe and effective for treating TON.

\section{Note}

This paper was presented at the 32nd Annual Conference of all India Rhinology Society, 2019, Chandigarh, India.

\section{Funding}

None.

Conflict of Interest

None declared.

\section{References}

1 Fujitani T, Inoue K, Takahashi T, Ikushima K, Asai T. Indirect traumatic optic neuropathy-visual outcome of operative and nonoperative cases. Jpn J Ophthalmol 1986;30(01):125-134

2 Wohlrab TM, Maas S, de Carpentier JP. Surgical decompression in traumatic optic neuropathy. Acta Ophthalmol Scand 2002;80 (03):287-293

3 Steinsapir KD, Goldberg RA. Traumatic optic neuropathy: a critical update. Comp Ophthalmol. Update. 2005;6(01):11-21

4 Sarkies N. Traumatic optic neuropathy. Eye (Lond) 2004;18(11): $1122-1125$

5 Wu N, Yin ZQ, Wang Y. Traumatic optic neuropathy therapy: an update of clinical and experimental studies. J Int Med Res 2008;36 (05):883-889

6 Horiguchi K, Murai H, Hasegawa Y, Mine S, Yamakami I, Saeki N. Endoscopic endonasal trans-sphenoidal optic nerve decompression for traumatic optic neuropathy-technical note. Neurol Med Chir (Tokyo) 2010;50(06):518-522

7 Li HB, Shi JB, Cheng L, Yun O, Xu G. Salvage optic nerve decompression for traumatic blindness under nasal endoscopy: risk and benefit analysis. Clin Otolaryngol 2007;32(06):447-451

8 Yu B, Ma YJ, Tu YH, Wu WC. Newly onset indirect traumatic optic neuropathy-surgical treatment first versus steroid treatment first. Int J Ophthalmol 2020;13(01):124-128

9 Ropposch T, Steger B, Meço C, et al. The effect of steroids in combination with optic nerve decompression surgery in traumatic optic neuropathy. Laryngoscope 2013;123(05): 1082-1086

10 Gross CE, DeKock JR, Panje WR, Hershkowitz N, Newman J. Evidence for orbital deformation that may contribute to monocular blindness following minor frontal head trauma. J Neurosurg 1981;55(06):963-966

11 Thaker A, Tandon DA, Mahapatra AK. Surgery for optic nerve injury: should nerve sheath incision supplement osseous decompression? Skull Base 2009;19(04):263-271

12 Hooper RS. Orbital complications of head injury. Br J Surg 1951;39 (154):126-138

13 Spoor TC, Mathog R. Restoration of vision after optic canal decompression following five days of total blindness and megadose steroid therapy. Arch Ophthalmol 1996;104:806

14 Lee V, Ford RL, Xing W, Bunce C, Foot B. Surveillance of traumatic optic neuropathy in the UK. Eye (Lond) 2010;24(02):240-250

15 Yang WG, Chen CT, Tsay PK, de Villa GH, Tsai YJ, Chen YR. Outcome for traumatic optic neuropathy-surgical versus nonsurgical treatment. Ann Plast Surg 2004;52(01):36-42

16 Song Y, Li H, Ma Y, et al. Analysis of prognostic factors of endoscopic optic nerve decompression in traumatic blindness. Acta Otolaryngol 2013;133(11):1196-1200

17 Rajiniganth MG, Gupta AK, Gupta A, Bapuraj JR. Traumatic optic neuropathy: visual outcome following combined therapy protocol. Arch Otolaryngol Head Neck Surg 2003;129(11): 1203-1206

18 Chaon BC, Lee MS. Is there treatment for traumatic optic neuropathy? Curr Opin Ophthalmol 2015;26(06):445-449

19 Li H, Zhou B, Shi J, Cheng L, Wen W, Xu G. Treatment of traumatic optic neuropathy: our experience of endoscopic optic nerve decompression. J Laryngol Otol 2008;122(12):1325-1329 